\title{
CHALLENGES IN DEFINING THE “CHILD”, “JUVENILE” AND “JUVENILE DELINQUENCY" IN THE INTERNATIONAL AND SRI LANKAN DOMESTIC LAW.
}

\section{Induwara Goonerathne}

\author{
Department of Forensic Medicine Faculty of Medicine University of Peradeniya.
}

The concepts of "Child" "Juvenile" and "delinquency" are three notions that legal and medico-legal communities categorically deals with. The concept of child is not only relevant to medico-legal practice in terms of managing child abuse but also dealing with juvenile delinquents. The Term child has diverse significations in the literature. These include and not limited to 'persons under the age of eighteen years of age', 'those who have not reached "majority" and "those who are under the age of fourteen'. Many "terms" such as "minor", "infant" "juvenile" "sub adult" are used interchangeably and confusingly to denote the "child" semantically, while each term tend to own its own literal meaning . Such terms may have different connotations all together in contexts of law.

The aim of this paper is to examine and evaluate the concept of "child", the concept of "juvenile" and the concept of "delinquency" and their definitions as applied in the law. Although several other disciplines (e.g psychology) may have many different additional terms to denote a "child" or a "juvenile", it is not the scope of this paper to examine such other disciplines other than the discipline of law. This conceptual analysis therefore is limited to the use of the term "child" and "juvenile" and similar terminology to denote a child or a juvenile in the legal literature and medico- legal case work.

The analysis and discussion of the above three major concepts in this study becomes important and relevant as it can highlight the confusing nature of the definitions and understanding of the terms, their limitations, issues and practical difficulties one can anticipate in applications of those terms in the juvenile justice process at the grass root levels especially in a developing country.

It is also important and relevant to understand as to how the notion of "child" "juvenile" or "delinquency" are perceived formed and shaped in the Sri Lankan culture. The definitions and the cultural acceptances of these notions tend to form an image of the "child" and "juvenile" in the society .If the image of the notions under study is not formed exactly as indicated by the international law, then the expectations of the international law would not be met. For example, if the cultural tendency is to treat older children as adults in the society in general, then it will be not plausible to reflect treatment of all children equally as children by the juvenile justice administration.

Three main arguments made are;

1. There is no consensus on the age limitation of childhood or juvenile in the law. Different laws have indicated different legal ages for identifying "children" which makes interpretation and appreciation quite confusing.

2. As a result of the variability of the age cap of a juvenile in the international law and local legal scenarios, the application of juvenile justice principles and child rights can vary. This situation undermines the universality nature of human rights and juvenile justice administrations.

3. The idea of delinquency is ambiguous in regard to children and unequally used between adults and children

International laws and domestic laws categorically use terms such as "child" and "juvenile" in official texts. For example in the 
"United Nations (UN) Child Rights Convention - (UNCRC) " the term "child" is predominantly used where as in Beijing Rules (UN Minimum Rules for the Administration of Juvenile Justice,1985) and Riyadh Guide Lines (UN Guidelines for the Prevention of Juvenile Delinquency,1990", the term "juvenile" is used to denote children and young people. Ironically, in research articles and in literary texts, terms 'child' and 'juvenile' are used interchangeably at times.

Biologically, a child (plural: children) is generally a human being between the stages of birth and puberty. But some vernacular definitions of a child include the foetus (as well), as being an unborn child. ${ }^{1}$ The legal definition of "child" generally refers to a "minor", otherwise known as a person younger than the age of majority. "Child" may also describe a relationship with a parent (such as sons and daughters of any age or, metaphorically, an authority figure, or signify group membership in a clan, tribe, or religion; it can also signify being strongly affected by a specific time, place, or circumstance, as in "a child of nature" or "a child of the Sixties'. Such varieties of terms being used to denote a "child" in the literature confuses a reasonable and a prudent individual who attempts to articulate "who actually a "child" is in true sense"? Having a dichotomy in the definition and perception of this pivotal concept within this thesis makes the juvenile justice practitioner hesitant or rather bias in either provision or ensuring protections or guarantees ensured in the juvenile justice jurisprudence. Having a mixed mindset in regard to who a child is invariably leads a juvenile justice practitioner for an ambiguous state especially when dealing with children in older ages. In other words, when the age is more towards the upper end of the spectrum, for example in "Straight 18" approach towards the age of 18 (see below) their tendencies to be treated as adults are greater.

The Merriam Webster Dictionary 2012 online version provides the following (among others) as the meaning of the term "child".
1. An unborn or a recently born human person

2. A young person especially between infancy and the youth

3. A person not yet of age

4. A son or a daughter of human parents

Examining the meaning provided for the term "child' in this well accepted dictionary it is apparent that this term is used vaguely to denote human beings ranging from foetuses to young age. An age at which a child becomes an adult is not stated in this definition and remains silent. As "any son or daughter of human parents" can include adults, this definition of child can be extended to include all human beings, as they are sons or daughters of 'some' "human parents". The inference that can be deduced according to this definition is that in general terms the upper age limit of the child is implicit wage and silent.

Merriam Webster English dictionary online version (2012) defines the term "Juvenile" as;

a) reflecting psychological or intellectual immaturity

b) physiologically immature or underdeveloped

c) relating or suitable for children.

Considering the above well accepted dictionary definition, a reasonable question arises as to whether those intellectually and psychologically disabled adults such as those who suffer from conditions such as "Autism" etc are also considered "juveniles" irrespective of their age merely taking into account their intellectual disability. Critically looking at the above dictionary definition of a juvenile, another reasonable question arises as to whether the term juvenile is a synonym for children. It is worth considering whether these two terms "child" and "juvenile" are used to mean the same "thing" or "person" in the law. The main international law that defines a "child" is the CRC (the UN Convention of the Rights of the Child). In the CRC the article 1 defines a child as "a child means every human being below the age of eighteen years unless under the law applicable to the child, majority is attained earlier". 
Considering the above international legal definition of a child two facts are relevant.

1. A child is a human person under the age of 18 years. This means that those who have already attained 18 or above are not considered children according to this law.

2. There is a provision provided within this definition for states to define when human persons could attain the age of majority. In other words if a state has already defined the age of majority to be lower than 18 ,children in that particular state would be those under such age of majority defined in the local law. For example, if a state has defined in its local law that the age of maturity/majority is 16 years hypothetically, for that particular local context "children" would be those under 16 years. Those above 16 would be considered adults in that particular state. The disadvantage of this provision is that those persons between the age of 16 and 18 will not be able to technically enjoy the protections guaranteed by the UNCRC in that particular country. However the international law does not allow the age of a child to be higher than that of 18 years. Further those who have attained majority are no longer children.

Two different other issues arise with this definition. The states are not provisioned to increase the age of majority above 18. Also, for those who do not have accurate recordings of their birth dates or who do not have valid documentations of proof of their age has a legitimate problem of enjoying the rights of the CRC. This affects mainly those who are around $15-18$ years of age. In criminal cases what generally happens is that such "children" who are unable to prove the age are produced to a medical practitioner to estimate the age. It has been accepted scientifically that an accurate "age" pointing to a particular year cannot be made on an individual based on biological evidence due to biological and other variations exist in human beings. In these instances those "children" would not be able to enjoy such privileges of CRC or juvenile justice.
According to the article 1 of the CRC it is obvious that those persons who have already reached the age of 18 will not be covered under CRC hence its protections as "a person should be below the age of 18 to enjoy the privileges of UNCRC

\section{The Age of the Child and the International Law}

The development of international human rights law and humanitarian laws have shaped and remodelled an internationally acceptable definition of a child. The main international legal instrument that categorically defines a child is the UN (United Nations) Convention of the Rights of the Child- CRC). This is the most widely accepted and widely ratified UN human rights instrument. The binding nature of the CRC on the nations that have ratified provides a legal obligation for the states to comply with its provisions and to ensure and protect the rights that have been guaranteed by it. The CRC attempts to present a "straight 18" definition for a child, which means that the age of the child could range from birth up to the age of 18 and not beyond the age of 18 . According to the CRC article 1 the definition of the child is stated as

"for the purposes of the present convention a child means every human being below the age of eighteen years of age unless under the law applicable to the child, majority is attained earlier".

The UN minimum rules for the administration of juvenile justice also known as "Beijing Rules" define a "juvenile" as follows under its general principles: section 2 .

"A juvenile is a child or a young person under the respective legal systems may be dealt with for an offense in a manner which is different from an adult"

In analyzing this "definition" it is obvious that there are two distinct categories that this international legal instrument deals with: Children and young persons. In other words, both children and young people belong to the 
category of "juvenile" according to the above international law. Thus, a juvenile is a child (one below 18 years of age) or a young person. As to "who is a young person", the Beijing rules or other international rules such as Havana Rules or Riyadh Guide lines concerning juvenile justice are silent,. What the international law has attempted in this situation is that, it has given provisions and discretion to individual states to define who a "young person" is that would suit each sociocultural context of the state. Therefore, there can be diversity in defining who a young person is in different states. For example, a young person can be those who are below 18 in accordance to one state's wish or it can be those who are between 18 years to 22 years. For example CYPO (the Children and Young Persons Ordinance in Sri Lanka) a child is a person under the age of 14 years and a young person is between the age of 14 to 16 years. The CYPO there for have no provisions for children between 16 to 18 . They are neither considered children nor young persons: Are they then adults?

As a result, a juvenile offender according to Beijing rules means a child offender or a young person who is alleged to have committed or who has been found to have committed an offense.

In accordance to the international acceptance, juvenile justice means the entire process of the management and administration of justice involving children or young persons as suspects / convicts and convicts ${ }^{2}$. However, by tradition and conception juvenile justice primarily involves children or young persons who are in conflict of "criminal law"3. Although there can be children or young people who can be in conflict with civil law, such offenders are not dealt within this specialized branch of law.

In accordance to the latest publication by "Save the Children, UK" , known as " Juvenile Justice- Modern concepts of working with children in conflict with the Law", the purview of juvenile justice extends beyond the management and administering crimes committed by juveniles to examining root causes of offending behaviour and taking measures to prevent such behaviours. Therefore Juvenile Justice scope has two distinct focus: prevention and protection of juveniles. The prevention aspect involves methods to ensure that the children do not come into conflict with the law in the first place and therefore do not come in to contact with the formal criminal justice system. Prevention aspect also includes addressing the issues of recidivism amongst child offenders. The focus of protection deals with measures that are needed to protect children and young persons who are already in conflict with the law and also to prevent them from re offending. This scope includes ensuring their basic human rights, procedural safeguards such as due process and best interest. The aim of the scope of juvenile justice is to ensure that the child offender is rehabilitated and integrated to the society in a useful manner ${ }^{4}$

It must also be mentioned that terms such as "youth" "adolescent" "minor" "infant" "sub adult" are also used in the society to include young people. However the usages of these terms are not unanimous and not consistent within societies. Therefore the use of the terms "juvenile" and "child" make sense in the law as they have been defined categorically for legal purposes.

The idea of "straight 18 " position indicated through the UNCRC is widely accepted in the international law. However in the international laws governing war or humanitarian laws attempt to prohibit engagement of children as child soldiers who are under the age of 15 . These ideas were extended through the protocols additional to the UNCHR. The additional protocols to the UNCHR or the Humanitarian law did not attempt to define a child but categorically indicated that "no child under the age of 15 can be used for combat related purposes"(CRC optional protocol,1). This situation creates an issue/tension regarding general values of human rights law. In the human rights law child conscription prohibition is accepted as a general value. The human rights law regards all persons under 18 
years of age as children. However, the optional protocol 1 of the UNCRC and Vienna Convention allows (thus indirectly) children over 15 years (15 years to 18 years to be specific) to be engaged in combat related activities. This seems the laws applying to war or armed conflict prefer to identify children as those who are above the age of 15 and as a result children between 15 to 18 years as adults?

Ideas about childhood and ideas about legal rights of children vary significantly among cultures. Many sovereign states and scholars have stressed and argued for a national definition of childhood in the law and enabling sovereign states to have discretion on establishing laws concerning childhood depending on individual cultural acceptances. It is with respect to this move especially from the eastern wing of the UN that the provision "unless under the law applicable to the child, majority is attained earlier" came about in the definition of child in the UNCRC article 1.

Another relevant International Law in this aspect of age of a child is the Minimum Age Convention 1973. The aim of the Minimum Age Convention (MAC) is to introduce a general legal framework on the subject of the minimum age for employment with a view to achieving the total abolition of child labour. Thus, each State Party is to "pursue a national policy designed to ensure the effective abolition of child labour and to raise progressively the minimum age for admission to employment to a level consistent with the fullest physical and mental development of young persons" (article 1). States Parties must specify a minimum age for admission to employment or work, subject to certain exceptions set forth in the MAC. That minimum may not be less than the age of completion of compulsory schooling and, in any case, less than fifteen years, but it may initially be set at fourteen years if a state's economy and educational facilities are insufficiently developed (article 2). Exceptions to the age limits may also be permitted for light work or for such purposes as participation in artistic performances (articles 7 and 8). If the employment may be hazardous to a young person's health, safety, or morals, the minimum age is generally not to be less than eighteen years (article 3(1)). If the aim of this important international law was to abolish child labour completely (its preamble) why then the instrument itself suggests an age around 15 as a minimum age for employment. This situation suggests that although in general terms persons under 18 years are considered to be children (UNCHR) in the general international law under special circumstances and for special purposes the age of children seem to be lowered to 15 (or to 14) . In the labour situation and in the law of war situation "children" between 15 to 18 are considered no longer children and more or less treated as adults.

This misleading situation makes it possible for juvenile justice practitioners to treat older children more like adults which is contrary to the expectations of the international law on children and juvenile justice.

In the US there are several judgments concerning the age of a "child". One such important case is Sheffield et al v Franklin 9 1907) Aa, 44 So Rep.373. In this adoption case the court held that the word "child" is used in the sense of relationship and not of infancy. At the time of adoption the age of the child was 26 years and the court held that he belongs to the category of a "child". Also in Markover v krauss, 132 Ind.297. 31 N.E !047,17 L.R.A.806 holds that the word "child" includes one having passed his majority because a child does not cease to be one's child after it has attained its majority. In Williams V Knight, 18 R I 333. 27 Atl 210: In re Moore, 14 R I 38 the court held that the term: child" means a minor child and not those who have attained majority. In this case three judges descent on the ground that "the word "child" can be and should be held to mean an infant. An infant according to this decision is a person under twenty one years, which was the age of majority.

The African Charter on the Rights and Welfare of the Child 1990 on the other hand 
categorically adopts the "straight 18 " status for children age. It does not include a discretion for the state concerned to establish an age of maturity below the age of 18 (the UNCRC allowed a discretion). The African Charter on the Rights and Welfare of the Child 1990 stipulates

"For tile purposes of this Charter. a child means every human being below the age of 18 years. (article-1)"

The European Convention on the 'Exercise of Children's Rights 1996' introduces the child as (in article-1) "this convention shall apply to children who have to reach the age 18 . This instrument also categorically applies the "straight 18 " rule as per the age of children.

\section{The Sri Lankan situation in law regarding children and juveniles}

There are several statutes that deal with children specifically in Sri Lanka.

1. Adoption of Children's Act 24 of 1956 which had several amendments subsequently.

2. Children and Young person's Act (CYPO) 48 of 1956- the main instrument that deals with juvenile justice

3. Convention on Prevention and combating trafficking in women and children for prostitution 30 of 2005

4. Employment of Women Young persons and Children 47 of 1956

5. Lanka Children and Youth theatre foundation

When perusing these laws it is clear that the Sri Lankan law recognizes two distinct groups as "children" and "young persons". The Adoption of Children's act in Sri Lanka does not specify the upper limit or lower limit age of a 'child' who can be adopted. The act seems to accept the general legal conditions prevailing in the country regarding the age span of child. Therefore this act does not provide a definition for a child or a juvenile but impliedly rely on the general accepted law as to the definition of a child. In the CYPO, which is the main local legal instrument that deals with juvenile justice in Sri Lanka, under interpretation section of the act, a child has been defined as "a person under the age of 14 years" .This interpretation is contrary to the UNCRC definition of a child which shall be under 18 years of age. The age of majority in Sri Lanka is 18 years of age. Since Sri Lanka has ratified the CRC, it is bound to comply with the provisions of the CRC. Further, in CYPO, a young person is identified as (section 88) "a person who has attained the age of fourteen years and is under the age of 16 years. Thus the children between 16 and 18 are excluded and seemingly redundant in this act in terms of child rights in the realm of juvenile justice. For those youthful offenders belonging to the age group from 16 years to 22 years, the Youthful offenders Training Schools Act (28 of 1956) applies. In this act, a youthful offender is identified as "a person who has attained the age of 16 and who has not attained the age of 22 years. On principle it is apparent that as the CYPO does not cover children between 16 years and 18 years are not eligible to be heard in a juvenile court. According to the Youthful Offenders Training School act a detention order can be given by any court and not necessarily by the juvenile court.

It is important and relevant for this study to appreciate as to how the childhood is understood in the international law and compare/contrast it with the domestic law in Sri Lanka.

Age is the deciding factor of the categorization of adults and children in any sphere. According to the foregoing discussion it is apparent that the international law and the domestic law have confusing and conflicting ideas about defining a child. However, for general purposes a child is defined as a person under 18 years (UNCRC). But the same international law that defines a child attempts to provide a provision for states to declare an age of majority (on its own peril) in which case the maximum age of a child could be arguably lower than 18 years of age. On the 
other hand, there are other international law that deals with children, for example those that are concerned with law of war and labour that indirectly identifies a child to be less than 18 years. A similar confusing situation exists in Sri Lankan law. The CYPO which is the main domestic law that deals with juvenile justice recognizes persons under 14 years as children and those who are within 14 years to 16 as juveniles. Further, there is an additional statute known as youthful offenders training school act 28 of 1956 which identifies those who have reached the age of 16 and who have not yet reached the age of 22 as youthful persons. In other words, the Sri Lankan law recognizes 3 categories, namely children (those who are under the age of 14) then the juveniles (ages between 14 to 16) and the youthful offenders (those who are between 16 and 22 years.) This dichotomy and confusing situation makes the task of implementing juvenile justice principles difficult, ambiguous and unequal.
Therefore, the "non consensus" on the age limitation of childhood or juvenile in the law that allows different laws to indicate different legal ages for identifying "children" and "young people" can make interpretation and appreciation of the law quite confusing thereby risking the application of juvenile justice principles to 'ambiguous' age groups.

\section{REFERENCES}

1. See Shorter Oxford English Dictionary 397 (6th ed. 2007), which's first definition is "A foetus; an infant;...". See also "The Compact Edition of the Oxford English Dictionary: Complete Text Reproduced Micrographically', Vol. I (Oxford University Press, Oxford 1971): 396, which defines it as: 'The unborn or newly born human being; foetus, infant'.

2. UN Minimum Rules for the Administration of Juvenile Justice:the Beijing Rules:sec 2.

3. Bernard J Thomas R'The Cycle of Juvenile Justice"(1992)Oxford University Press.

4. Juvenile Justice- Modern concepts of working with children in conflict with the Law by Save the Children, UK, 2004. 